\title{
Clinical Reasoning: A 64-year-old woman with progressive leg weakness and ophthalmoplegia
}

Ryan T. Muir, BHSc, MD, * Agessandro Abrahao, MD, MSc, * David Fam, MD, and Lorne Zinman, MD, MSc Neurolog ${ }^{\circledR}$ 2020;95:e2170-e2173. doi:10.1212/WNL.0000000000010363
Correspondence

Dr. Zinman

lorne.zinman@

sunnybrook.ca

\section{Section 1}

A 64-year-old woman with type 2 diabetes (HbA1C: 6.6\%) experienced pain radiating down her right leg with intermittent numbness and tingling in her feet, followed by right leg weakness and recurrent falls. Two months after onset, she required a walker to ambulate long distances. Over the next 5 months, she experienced slow and progressive right leg weakness. Her neurologic examination revealed normal cranial nerves, fasciculations in the right leg, and nonpyramidal weakness in the right L3-S1 myotomes. She had intact strength elsewhere. Reflexes were pathologically brisk (3+), except for absent right patellar and bilateral Achilles reflexes. Plantar responses were flexor. There was mild length-dependent distal sensory loss in both lower extremities.

Nerve conduction studies (NCSs) revealed attenuated motor responses throughout the right leg with relative sparing of conduction velocity. There was no motor conduction block or evidence of demyelination. Sensory responses were absent in both legs. Needle EMG revealed ongoing neurogenic denervation in multiple bilateral lumbosacral and right thoracic myotomes.

\section{Questions for consideration:}

1. What is the expected localization of this patient's deficits?

2. What is the differential diagnosis?

GO TO SECTION 2 


\section{Section 2}

Given the patient's asymmetric nonpyramidal weakness, fasciculations, and sensory loss, this process localizes to lumbosacral lower motor neurons (LMNs) and peripheral nerves. A right lumbosacral radiculoplexus neuropathy with superimposed diabetic sensory polyneuropathy was considered. However, neurogenic denervation spreading to thoracic myotomes and the clinically unaffected leg argued against a unilateral radiculoplexopathy. Overall, the presentation suggested more LMN dysfunction, but pathologically brisk reflexes suggested early upper motor neuron (UMN) involvement.

Although the patient's sensory findings and lack of weakness in other limbs was atypical, the presence of both LMN and UMN findings was suspicious for an LMN-predominant motor neuron disease (MND), such as a variant of amyotrophic lateral sclerosis (ALS), with superimposed diabetic polyneuropathy. The differential diagnosis also included motor neuronopathy and motor neuropathy, such as multifocal motor neuropathy and multifocal acquired motor axonopathy, along with diabetic sensory polyneuropathy. She had normal serum $\mathrm{B}_{12}$, ceruloplasmin, protein electrophoresis, thyroid-stimulating hormone, and inflammatory panel. Creatine kinase was mildly elevated as can be seen in axonal neuropathy and MND. Nonenhanced MRI spine was normal aside from L5/S1 spondylolisthesis and moderate foraminal stenosis.

For the next 4 months, the patient remained stable. However, 11 months after her initial symptoms, she developed 5 weeks of progressive upper extremity weakness, falls, diplopia, dyspnea, and dysphagia with 25 pounds of weight loss. She noted binocular horizontal diplopia with lateral gaze, which progressed to complete paresis of horizontal gaze. She also noticed new numbness and tingling in her left leg and bilateral hands that progressed up her left arm to the elbow. There were no accompanying cognitive changes, seizures, or fevers.

The patient's examination revealed normal visual acuity and fields. Convergence and vertical gaze were intact, but horizontal eye movements were absent bilaterally. This was not overcome by the vestibulo-ocular reflex (VOR). There was LMN bilateral facial paresis. The palate elevated symmetrically, and her tongue had normal movements without fasciculations. Her speech was dysarthric. She had a brisk jaw-jerk reflex. Her motor examination revealed reduced bulk and fasciculations in the right quadriceps. Mild nonpyramidal weakness was noted in neck flexors, deltoids, and biceps bilaterally. Worsened nonpyramidal weakness was noted in the right leg. Weakness was not appreciated in the left leg. Reflexes remained pathologically brisk in the upper extremities, but were absent in the legs. Her left plantar response was flexor, but mute on the right. She had reduced vibration sense distally in the lower extremities.

\section{Questions for consideration:}

1. Where do the patient's ocular findings localize?

2. Does this new presentation revise your previous differential diagnosis?

3. What additional investigations are indicated now?

\section{GO TO SECTION 3}




\section{Section 3}

Bilateral horizontal gaze paresis not overcome by VOR, preserved convergence, and bilateral facial paresis localizes to the pons at the level of the facial colliculus, involving bilateral cranial nerve VI nuclei and the fascicles of cranial nerve VII. MRI demonstrated increased T2 fluid-attenuated inversion recovery signal in the posterior pons (figure).

Although ophthalmoplegia can rarely occur in bulbar ALS and impairment in extraocular movements occurs as a late manifestation of ALS in chronically ventilated patients, ophthalmoplegia is atypical of ALS. One consideration, given the patient's dysphagia and weight loss, was a superimposed Wernicke causing ophthalmoplegia. However, the patient's condition continued to worsen despite high-dose IV thiamine. Although progressive supranuclear palsy (PSP) and multisystem atrophy (MSA) can rarely co-occur with MND, the absence of vertical eye movement abnormalities, parkinsonism, autonomic dysfunction, and ataxia was not consistent with PSP or MSA. Although the examination and EMG revealed predominant LMN dysfunction, the rapidity of decline, worsened sensory symptoms, ophthalmoplegia, and pontine lesion challenged the diagnosis of ALS and broadened our differential to include inflammatory, paraneoplastic, and autoimmune etiologies affecting motor neurons and cranial nerve nuclei.

A CT chest, abdomen, and pelvis and transvaginal ultrasound did not reveal evidence of malignancy or lymphadenopathy. CSF analysis revealed protein of $503 \mathrm{mg} / \mathrm{L}$, but otherwise cytology, cytometry, and extensive bacterial and viral studies were unremarkable. Serum anti-GQ1b, anti-GM1, and Lyme serology were negative. Repeated NCS revealed new-onset patchy, non-length-dependent loss of sensory responses in the left upper extremity. The patient was started on high-dose methylprednisolone and IV immunoglobulin (IVIg) without clinical improvement. The patient developed progressive respiratory decline, disorientation, and lethargy. An EEG did not reveal evidence of seizures and repeated MRI brain remained stable. The patient continued to decline and eventually died of respiratory failure. Her paraneoplastic antibody panel later revealed positive serum and CSF anti-Hu antibodies. The family declined autopsy.

\section{Discussion}

This clinical reasoning case highlights the challenges of diagnosing atypical motor neuropathies and LMN-predominant ALS. Without a reliable biomarker, upwards of $10 \%$ of ALS cases are erroneously diagnosed. ${ }^{1}$ Cervical spondylotic myeloradiculopathy, polyradiculopathy, MSA, and multifocal motor neuropathy are conditions erroneously misdiagnosed as ALS. ${ }^{1}$ The diagnosis is especially challenging early in the disease when UMN and LMN signs have not disseminated. Initially, the clinical evidence of LMN and mild UMN involvement early in our patient's disease course, as well as ongoing neurogenic denervation in multiple thoracic and lumbosacral myotomes, satisfied the revised El Escorial diagnostic criteria for probable ALS-laboratory-supported. ${ }^{1}$

Rarely, paraneoplastic disorders can cause MND and masquerade as ALS, the most common of which is anti-Huassociated MND. ${ }^{2}$ Paraneoplastic MND can be pure LMN syndromes in $63 \%$ of cases and both LMN and UMN presentations in $37 \%$ of cases. ${ }^{3}$ Paraneoplastic MND should be suspected in those under 40 years of age, with known

Figure Axial MRI demonstrating increased T2-fluid-attenuated inversion recovery (FLAIR) signal in the posterior pons

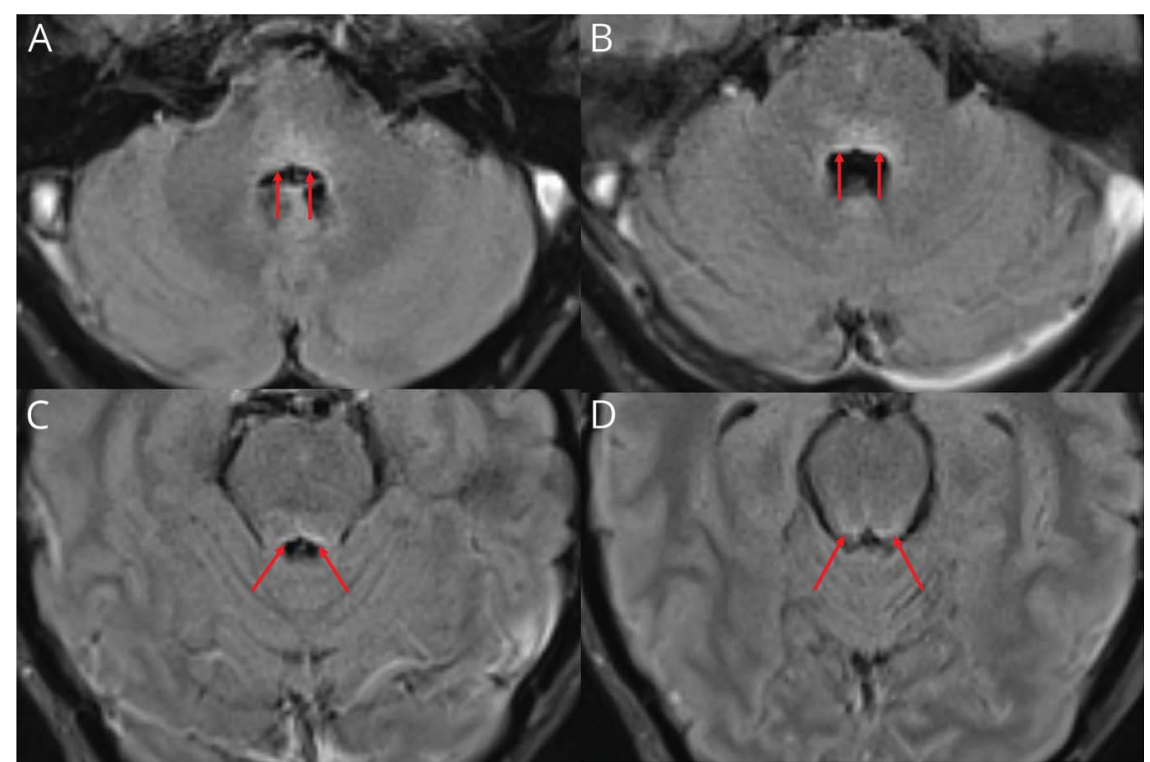

Axial MRI T2 FLAIR demonstrating increased signal hyperintensity in the posterior pons (as indicated by the red arrows). In the caudal pons, depicted in A and B, T2-FLAIR signal hyperintensities are visualized affecting the region of the bilateral facial colliculi and cranial nerve VI nuclei. T2-FLAIR signal hyperintensities continue into the rostral pons as indicated by the red arrows in C and D. There was no associated parenchymal, leptomeningeal, or cranial nerve enhancement with MRI T1 postgadolinium imaging. There was no evidence of restricted diffusion on diffusion-weighted imaging/apparent diffusion coefficient modalities. The remaining MRI brain and spine were both unremarkable. 
malignancy, rapid progression, subacute onset, extramotor neuron involvement, monoclonal gammopathy, lymphadenopathy, or elevated inflammatory markers. ${ }^{2}$ Indeed, the rapid and profound weakness in the right leg without clinical involvement of the left leg is atypical for ALS. Diabetes could explain the initial length-dependent distal sensory symptoms, but the new onset of patchy sensory loss represented another red flag for an extramotor process affecting the dorsal root ganglia, likely secondary to anti-Hu. When the patient rapidly deteriorated with ophthalmoplegia, it was clear that she did not have ALS.

This is the first reported case of anti-Hu antibody-associated ophthalmoplegia and MND. Anti-Hu-associated MND was first reported in 1995 in the context of small cell lung cancer (SCLC) with demonstrated loss of anterior horn cells, neurogenic denervation, and loss of cerebellar Purkinje cells. ${ }^{4}$ The clinical spectrum of anti-Hu paraneoplastic disorders has since expanded to include limbic and brainstem encephalitis, encephalomyelitis, sensory neuronopathy, Lambert-Eaton syndrome, and opsoclonus myoclonus. ${ }^{5}$ Ophthalmoplegia has been reported recently in a patient with liposarcoma and anti-Hu antibodies, but without MND. ${ }^{6}$ Anti-Hu syndromes are most often associated with SCLC ( $85 \%$ of cases), but have been reported in lymphoma, neuroblastoma, and pancreatic neuroendocrine tumors, as well as prostate, intestinal, bladder, and ovarian carcinomas. ${ }^{5}$ In a study of 200 anti-Hupositive cases, no tumor was found in 33 patients. ${ }^{5}$ In another study of 20 patients with paraneoplastic antibodies and without evidence of malignancy, PET had $83 \%$ sensitivity in detecting a cancer. ${ }^{7}$ In this study, 13/20 patients had Anti-Hu antibodies and 8 of 9 patients who died during the study were Anti-Hu positive.

The importance of rapidly identifying onconeural antibodies with prompt treatment of malignancy in paraneoplastic MND was highlighted by cases of SCLC with chemotherapyresponsive anti-Hu MND. ${ }^{8}$ Furthermore, in a single case report, a patient with SCLC and anti-Hu-associated limbic encephalitis and MND stabilized with IVIg treatment and survived to receive radiotherapy with remission and neurologic improvement. ${ }^{9}$ Therefore, patients with atypical motor neuronopathy should have paraneoplastic antibody screening and, if identified, extensive imaging, including PET, should be performed. In those with a paraneoplastic antibody, consensus opinion continues to recommend prompt cancer screening and treatment of the primary cancer as the optimal intervention. $^{10}$

This case expands on the clinical spectrum of anti-Hu paraneoplastic disorders. This is the first reported description of a patient with MND and ophthalmoplegia associated with anti$\mathrm{Hu}$ antibodies. The prevalence of paraneoplastic-associated MND is unknown and likely rare, but this etiology should be included in the differential diagnosis for patients presenting with atypical forms of motor neuronopathy or MND. It is especially important to identify ALS mimickers that are potentially treatable as earlier identification and interventions might predict a more favorable prognosis.

\section{Study funding}

No targeted funding reported.

\section{Disclosure}

The authors report no disclosures relevant to the manuscript. Go to Neurology.org/N for full disclosures.

Appendix Authors

\begin{tabular}{|c|c|c|}
\hline Name & Location & Contribution \\
\hline $\begin{array}{l}\text { Ryan T. } \\
\text { Muir, MD }\end{array}$ & $\begin{array}{l}\text { Adult Neurology Residency } \\
\text { Training Program, } \\
\text { University of Toronto, } \\
\text { Canada }\end{array}$ & $\begin{array}{l}\text { Study conception and } \\
\text { design, equally drafted the } \\
\text { manuscript for intellectual } \\
\text { content, revised } \\
\text { manuscript for intellectual } \\
\text { contribution }\end{array}$ \\
\hline $\begin{array}{l}\text { Agessandro } \\
\text { Abrahao, } \\
\text { MD, MSc }\end{array}$ & $\begin{array}{l}\text { Division of Neurology, } \\
\text { Department of Medicine, } \\
\text { Sunnybrook Health } \\
\text { Sciences Centre, University } \\
\text { of Toronto, Canada }\end{array}$ & $\begin{array}{l}\text { Study conception and } \\
\text { design, EMG/NCS study } \\
\text { interpretation, equally } \\
\text { drafted the manuscript for } \\
\text { intellectual content, } \\
\text { revised manuscript for } \\
\text { intellectual contribution }\end{array}$ \\
\hline $\begin{array}{l}\text { David Fam, } \\
\text { MD }\end{array}$ & $\begin{array}{l}\text { Division of Neurology, } \\
\text { Department of Medicine, } \\
\text { Sunnybrook Health } \\
\text { Sciences Centre, University } \\
\text { of Toronto, Canada }\end{array}$ & $\begin{array}{l}\text { Major role in acquisition of } \\
\text { data, manuscript } \\
\text { preparation, critical review } \\
\text { of manuscript edits }\end{array}$ \\
\hline $\begin{array}{l}\text { Lorne } \\
\text { Zinman, } \\
\text { MD, MSc }\end{array}$ & $\begin{array}{l}\text { Division of Neurology, } \\
\text { Department of Medicine, } \\
\text { Sunnybrook Health } \\
\text { Sciences Centre, University } \\
\text { of Toronto, Canada }\end{array}$ & $\begin{array}{l}\text { Supervision, study } \\
\text { conception and design, } \\
\text { EMG/NCS study } \\
\text { interpretation, manuscript } \\
\text { preparation, acquisition of } \\
\text { data, final approval of } \\
\text { manuscript }\end{array}$ \\
\hline
\end{tabular}

\section{References}

1. Cortés-Vicente E, Pradas J, Marín-lahoz J, et al. Early diagnosis of amyotrophic lateral sclerosis mimic syndromes: pros and cons of current clinical diagnostic criteria. Amyotroph Lateral Scler Front Degener 2017;18:333-340.

2. Corcia P, Gordon PH, Camdessanche JP. Is there a paraneoplastic ALS? Amyotroph Lateral Scler Front Degener 2015;16:252-257.

3. Mélé N, Berzero G, Maisonobe T, et al. Motor neuron disease of paraneoplastic origin: a rare but treatable condition. J Neurol 2018;265:1590-1599.

4. Verma A, Berger JR, Snodgrass S, Petito C. Motor neuron disease: a paraneoplastic process associated with anti-Hu antibody and small-cell lung carcinoma. Ann Neurol 1996;40:112-116.

5. Graus F, Keime-Guibert F, Rene R, et al. Anti-Hu-associated paraneoplastic encephalomyelitis: analysis of 200 patients. Brain 2001;124:1138-1148.

6. Chan JW. Subacute complete ophthalmoplegia: an anti-Hu paraneoplastic manifestation of myxoid liposarcoma. Clin Exp Ophthalmol 2007;35:491-492.

7. Younes-Mhenni S, Janier MF, Cinotti L, et al. FDG-PET improves tumour detection in patients with paraneoplastic neurological syndromes. Brain 2004;127:2331-2338.

8. Goodfellow J, Gorrie G, Leach V, Patel S, Mackay G. Cancer and motor neuron disease: causal or coincidental? Two contrasting cases. Neurol Sci 2019;40: 1461-1463.

9. Cheli M, Dinoto A, Ridolfi M, Sartori A, Stokelj D, Manganotti P. Motor neuron disease as a treatment responsive paraneoplastic neurological syndrome in patient with small cell lung cancer, anti-Hu antibodies and limbic encephalitis. J Neurol Sci 2019;400:158-159.

10. Keime-Guibert F, Graus F, Fleury A, et al. Treatment of paraneoplastic neurological syndromes with antineuronal antibodies (Anti-Hu, Anti-Yo) with a combination of immunoglobulins, cyclophosphamide, and methylprednisolone. J Neurol Neurosurg Psychiatry 2000;68:479-482. 


\section{Neurology}

\section{Clinical Reasoning: A 64-year-old woman with progressive leg weakness and ophthalmoplegia}

Ryan T. Muir, Agessandro Abrahao, David Fam, et al.

Neurology 2020;95;e2170-e2173 Published Online before print July 17, 2020

DOI 10.1212/WNL.0000000000010363

\section{This information is current as of July 17, 2020}

\section{Updated Information \&} Services

References

Subspecialty Collections

Permissions \& Licensing

Reprints including high resolution figures, can be found at: http://n.neurology.org/content/95/15/e2170.full

This article cites 10 articles, 1 of which you can access for free at: http://n.neurology.org/content/95/15/e2170.full\#ref-list-1

This article, along with others on similar topics, appears in the following collection(s):

Amyotrophic lateral sclerosis

http://n.neurology.org/cgi/collection/amyotrophic_lateral_sclerosis_ Ocular motility

http://n.neurology.org/cgi/collection/ocular_motility

Paraneoplastic syndrome

http://n.neurology.org/cgi/collection/paraneoplastic_syndrome

Information about reproducing this article in parts (figures,tables) or in its entirety can be found online at:

http://www.neurology.org/about/about_the_journal\#permissions

Information about ordering reprints can be found online:

http://n.neurology.org/subscribers/advertise

Neurology ${ }^{\circledR}$ is the official journal of the American Academy of Neurology. Published continuously since 1951, it is now a weekly with 48 issues per year. Copyright () 2020 American Academy of Neurology. All rights reserved. Print ISSN: 0028-3878. Online ISSN: 1526-632X.

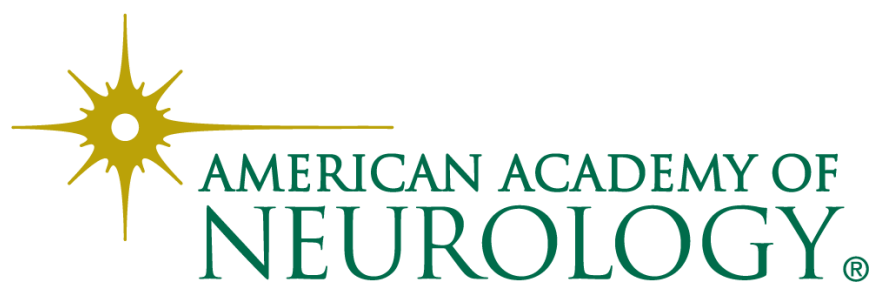

